\title{
PSYCHE
}

\begin{tabular}{lll}
\hline Vol. 86 June-September, 1979 & No. 2-3 \\
\hline
\end{tabular}

\section{THE NATURAL HISTORY OF THE FLIGHT OF HONEY BEE SWARMS}

\author{
By Thomas D. Seeley, ${ }^{1}$ Roger A. Morse ${ }^{2}$ and \\ P. KIRK VISSCHER ${ }^{2}$
}

\section{INTRODUCTION}

The flight of honey bee (Apis mellifera) swarms is the most spectacular and yet one of the least understood aspects of honey bee social behaviór. Over open countryside a flying swarm forms a small cloud, a swirling mass of some ten to twenty thousand individuals, loudly buzzing along at head height en route to a new home. There have been several studies of the behavior of a swarm as it emerges from its nest, clusters at an interim site, and there selects a new nest site (reviewed by Ambrose 1976 and Seeley and Morse 1978), but no one had ever recorded in detail the subsequent events of the longdistance flight to the new nest site. Moreover, a close analysis of honey bee swarm flight held the promise of clearly demonstrating division of labor within an insect society, in this instance between the scouts and nonscouts in honey bee swarms.

The present account treats only the period from agreement upon the new nest site to the entrance of the swarm into its new home. We took special pains to record events simultaneously at the interim cluster site and the new nest site throughout this period. Only in this way could we begin to picture the full complexity of the social organization underlying honey bee swarm flight.

\section{Materials AND Methods}

Study Sites. Most of the study was conducted in August 1979 at the Shoals Marine Laboratory on Appledore Island, Maine. This treeless, 39-ha island lies $16 \mathrm{~km}$ offshore and lacks natural nest sites for

\footnotetext{
'Museum of Comparative Zoology, Cambridge, Massachusetts, 02138

${ }^{2}$ Department of Entomology, Cornell University, Ithaca, N.Y. 14853

Manuscript received by the editor November 22, 1979.
} 
honey bees. Thus the swarm of bees we took to the island was forced to adopt the nestboxes we provided, and this simplified observing events at both the swarm's cluster site and future nest site. Besides this island work, we made one preliminary measurement of swarm flight velocity during July 1979 at the Dyce Laboratory, Cornell University.

Swarm Preparation. Artificial swarms were prepared from colonies at Dyce Lab using the standard techniques described by Seeley (1977). The genetic composition of each of these swarms was a mixture of the various honey bee races imported for American apiculture. However, the bees were light brown and so apparently were primarily of Apis mellifera lingustica (Italian bee) stock. The swarms weighed about $1400 \mathrm{~g}$ and so contained approximately 11,000 bees, a typical size for natural honey bee swarms (Fell et al. 1977).

Experimental Layout and Recording Techniques. We positioned the Appledore Island swarm on the island's western shore between Babb's Cove and Pepperrell Cove. We forced the swarm to cluster on a wooden cross (150 cm high with a $46-\mathrm{cm}$-long cross member) by confining the swarm's queen in a Benton mailing cage for queens, lashing this to the cross, and then releasing the swarm's workers. When they were fully clustered around the caged queen, we uncorked her cage so she could later fly away with the swarm. A 1-liter feeder jar filled with a $50 \%$ sucrose solution provided a constant food supply for the swarm.

We observed the island swarm perform two complete flights to a new nest site. Unless stated otherwise, the observations reported below are based on this swarm's second flight. The first flight was to a 5-frame hive placed $350 \mathrm{~m}$ away in the storage shed behind the Coast Guard building. After making this flight, the swarm was carried in the hive back to the wooden cross, its queen was recaged, and its workers were repositioned on the cross. The second flight followed the same line as the first, but continued along it for a considerably greater distance, approximately $580 \mathrm{~m}$. The second flight's nest site was a 40-liter bait hive (Morse and Seeley 1978) placed inside a small, lean-to shelter beside Devil's Glen on the easternmost point of the island.

We measured the Appledore swarm's flight velocities by laying out a series of 13 stakes spaced $30 \mathrm{~m}$ apart starting from the wooden cross and continuing out along the line leading to the nest sites. This 
line of markers was complete for the nearer nest site, but did not reach the farther one. Unbroken stretches of poison ivy shrubs (Rhus toxicodendron) prevented us from extending the line of spaced stakes beyond $390 \mathrm{~m}$. We timed the swarm's passing of each distance marker when the swarm cloud's center was over a marker.

Observations at the swarm cluster and nest site were coordinated using walkie-talkies. Because events unfolded very rapidly during swarm flights, we recorded our observations using continuouslyrunning tape recorders.

The flight velocity of the Dyce Lab swarm was measured using a different technique than described above. We placed the swarm on a cross just as already described, but allowed it to select a nest site freely in the woodlands about the laboratory. We measured its flight velocity by sprinting along beneath the flying swarm and periodically jabbing marker stakes in the ground. Time intervals between stakes were recorded by carrying a continuously-running tape recorder and noting aloud the moment of each stake's placement; distance intervals were later measured using a steel tape. Unfortunately, because of fences and tracts of brush, we could not follow the swarm all the way to its nest site.

Labelling Scout Bees. A fraction of the scout bees in the Appledore Island swarm were labelled before the swarm's first flight by painting a blue dot on every bee that danced for our nestbox. The paint was shellac mixed with artist's pigment, as described by von Frisch (1967).

\section{RESUlts AND Discussion}

\section{Return of Scouts from Nest Site to Swarm Cluster}

Observations made during studies of nest site hunting by honey bees (Lindauer 1955, Seeley 1977) suggested that once a swarm has decided which nest to occupy, the next step in the swarm movement process is the return of the scouts at the nest site to the swarm cluster. To document this phenomenon we made a count every 30 sec, starting 75 min before the swarm lifted off, of the number of scouting bees visible at the nest site. To simultaneously monitor the accumulation of scouts back at the swarm, we made periodic counts of the number of blue-marked scouts visible on the swarm cluster.

The return of the scouts is clearly shown in Fig. 1. Starting about $30 \mathrm{~min}$ before lift-off the number of bees at the nestbox began to decline; the number of marked scouts on the swarm was simultane- 
ously increasing. Buzzing runs (Schwirrlaufen) performed by some scouts at the nest site apparently triggered this retreat, since their occurence coincided with the start of the scouts' departures (see Fig. 1). Moreover, buzzing runs have been observed in two other contexts involved in swarming - when a swarm first leaves its nest, and later when a swarm lifts off from its interim cluster site; and in both cases the buzzing runs seem to signal "Let's go!" (Lindauer 1955, Martin 1963).

We counted all buzzing runs performed on the outside of the nestbox during each interval, but probably the majority were performed inside. The behavior of the buzz runners (Schwirrläuferin) we observed matched the descriptions of Lindauer (1955), Martin (1963), and Esch (1967) for buzz runners observed during nest departure and swarm lift-off. They made excited zig-zag runs over

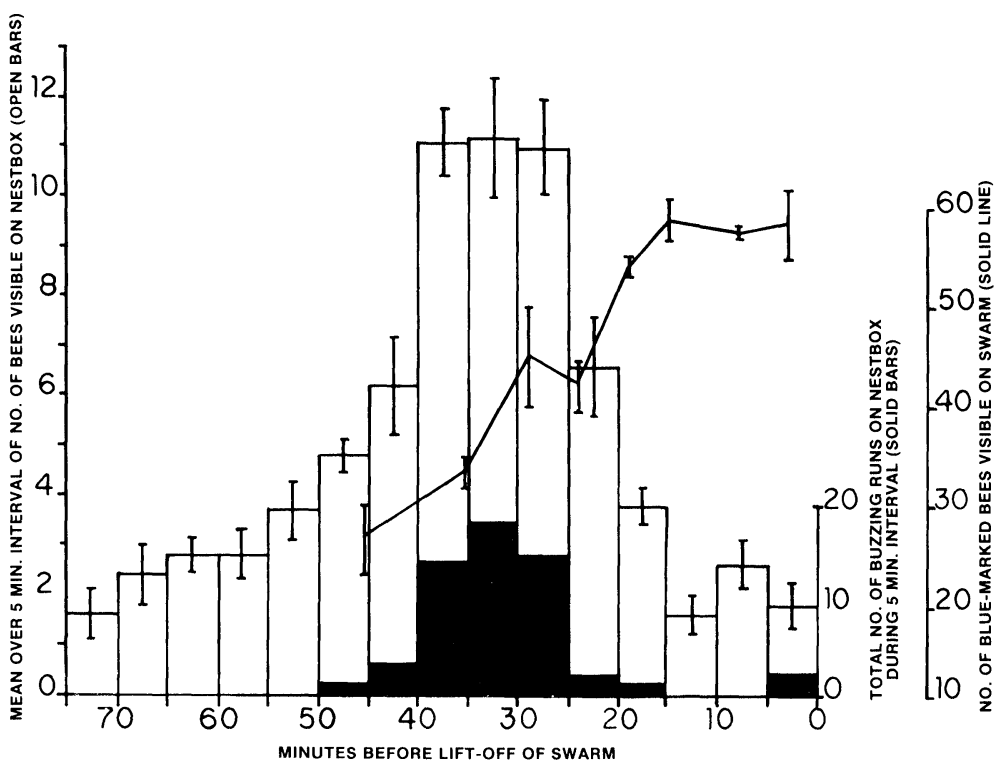

Fig. 1. Mean over $5 \mathrm{~min}$ interval of counts each $30 \mathrm{sec}$ of the number of bees visible on the nestbox (open bars, left scale), total number of buzzing runs observed on the nestbox during 5 min interval (solid bars, near right scale), and number of blue-marked scouts visible on the swarm cluster at various times (solid line, far right scale) as time of swarm flight approached. Vertical bars denote plus and minus one standard error. Counts document the return of the scouts from the nest site to the swarm cluster in preparation for the swarm's flight to the nest site. Buzzing runs at the nestsite apparently trigger the scouts' return. 
the nestbox surface, punctuated by bursts of wing buzzing. They would butt against individual nestmates and, buzzing steadily, attempt to bulldoze through small clusters of scouts. Esch's (1967) analysis of these movements reveals that when running about a buzz runner produces short pulses of $180-250 \mathrm{~Hz}$ wing vibrations, and then shifts to steady blasts of $500 \mathrm{~Hz}$ buzzing when contacting other bees.

The importance of the scouts' return to the swarm was revealed when we measured what fraction of the swarm had visited the nest site before the entire swarm flew there. This was done while awaiting the island swarm's first flight by recording over the last $60 \mathrm{~min}$ before lift-off the fraction of bees visible at the nestbox that were marked with blue. We marked 143 bees; the percentage of bluemarked bees among the bees observed at the nestbox, based on 130 counts, was $28.9 \% \pm 16.3 \%$ ( $\bar{x} \pm 95 \%$ confidence margins). Thus approximately 495 bees from the swarm (95\% confidence limits: 316-877 bees), or only about $5 \%$ of the swarm, had visited the nest site before lift-off. ${ }^{3}$ Evidently only a very small minority of a swarm's bees knows the precise location of the new nest site, and it is their task to guide the large majority to the new home. Because the ratio of ignorant to informed (scout) bees is so large, it appears important that as many scouts as possible be back at the swarm when lift-off occurs to guide the swarm to the new nest site.

\section{Lift-off of Swarm}

Upon returning to the swarm, some of the blue-marked scouts sat quietly on the swarm cluster, others resumed their dances advertising the chosen nest site, and still others began performing buzzing runs across the swarm's surface. The first vigorous, distinct buzz runner was sighted $43 \mathrm{~min}$ before lift-off, the second at $33 \mathrm{~min}$, the third at $26 \mathrm{~min}$, and by $18 \mathrm{~min}$ before lift-off 4 vigorous buzz runners were seen simultaneously scrambling over the swarm. Concurrent with the rise in buzzing run frequency came an increase in the intensity of a much higher-pitched piping sound. We could neither identify which bees were producing this sound, nor had we the means of characterizing it or of quantifying its intensification.

\footnotetext{
${ }^{3}$ This $5 \%$ estimate is actually an overestimate since only 46 of the 143 blue-marked bees had been painted by the time the proportion counts began at the nest box. Therefore early estimates of the proportion of marked bees were smaller than if all 143 bees had been marked and so, in turn, the net average of $28.9 \%$ of the nestbox bees being marked is an underestimate of the fraction of scouts which were painted.
} 
Perhaps this is the $5000 \mathrm{~Hz}$ sound which Esch (1967) found superimposed on the $500 \mathrm{~Hz}$ wing buzzes generated by buzz runners.

In the final 3 min preceding lift-off, the swarm teemed with buzz runners scrambling over the clustered bees, vibrating their wings and boring through the interlocked nets of hanging bees. A loud humming noise radiated from the cluster, a mixture of the deep wing buzzes and shrill piping sounds. This climaxed as the once solid surface of the swarm appeared to melt as the chains of hanging bees began disintegrating, and within 50 more sec the entire swarm was airborne, filling the air with the roar of 11,000 bees tightly circling just overhead.

\section{Cross-Country Flight of the Swarm}

The movement of the airborne swarm began very slowly. Fig. 2 shows that in both flights the island swarm traversed the first $30 \mathrm{~m}$ with an average velocity of just slightly over $1 \mathrm{~km} / \mathrm{h}$. This slow start may reflect the swarm's checking for the airborne presence of the queen, signalled by the odor of (E)-9-oxodec-2-enoic acid (Avitabile et al. 1975), or the difficulty of getting the thousands of bees moving en masse in the proper direction, or both. Immediately after lift-off the swarm cloud was circular in horizontal cross-section, with a diameter of about $10 \mathrm{~m}$, as estimated from the 30 -m-spaced stakes along the flight path. Its vertical cross-section was roughly circular, though with the bottom somewhat flattened along an imaginary line about $2 \mathrm{~m}$ above the open ground.

Not all the swarm's bees stayed with the slow-moving swarm cloud; a few shot out ahead to the nest site where they settled at the nest entrance and began releasing assembly pheromones from their Nasanov glands (reviewed by Wilson 1971, Michener 1974). Fig. 3 shows that there were 2 bees visible and scenting at the nest site 580 $\mathrm{m}$ away even before the swarm cloud had crossed the $30 \mathrm{~m}$ marker.

By the time the swarm had flown $60 \mathrm{~m}$, its velocity had increased to over $4 \mathrm{~km} / \mathrm{h}$ and it continued to increase through at least the 210 $\mathrm{m}$ mark to 8.5 and $11.0 \mathrm{~km} / \mathrm{h}$ maximum speeds on the first and second flights, respectively (see Fig. 2). Swarm shape also changed over the first $60 \mathrm{~m}$. The swarm cloud became more flattened top-tobottom so that its vertical cross-section was ovoid, about $10 \mathrm{~m}$ long and $3 \mathrm{~m}$ high. The swarm's front was angled upward slightly, with the bottom of the swarm about $1 \mathrm{~m}$ above the tops of the bushes, 


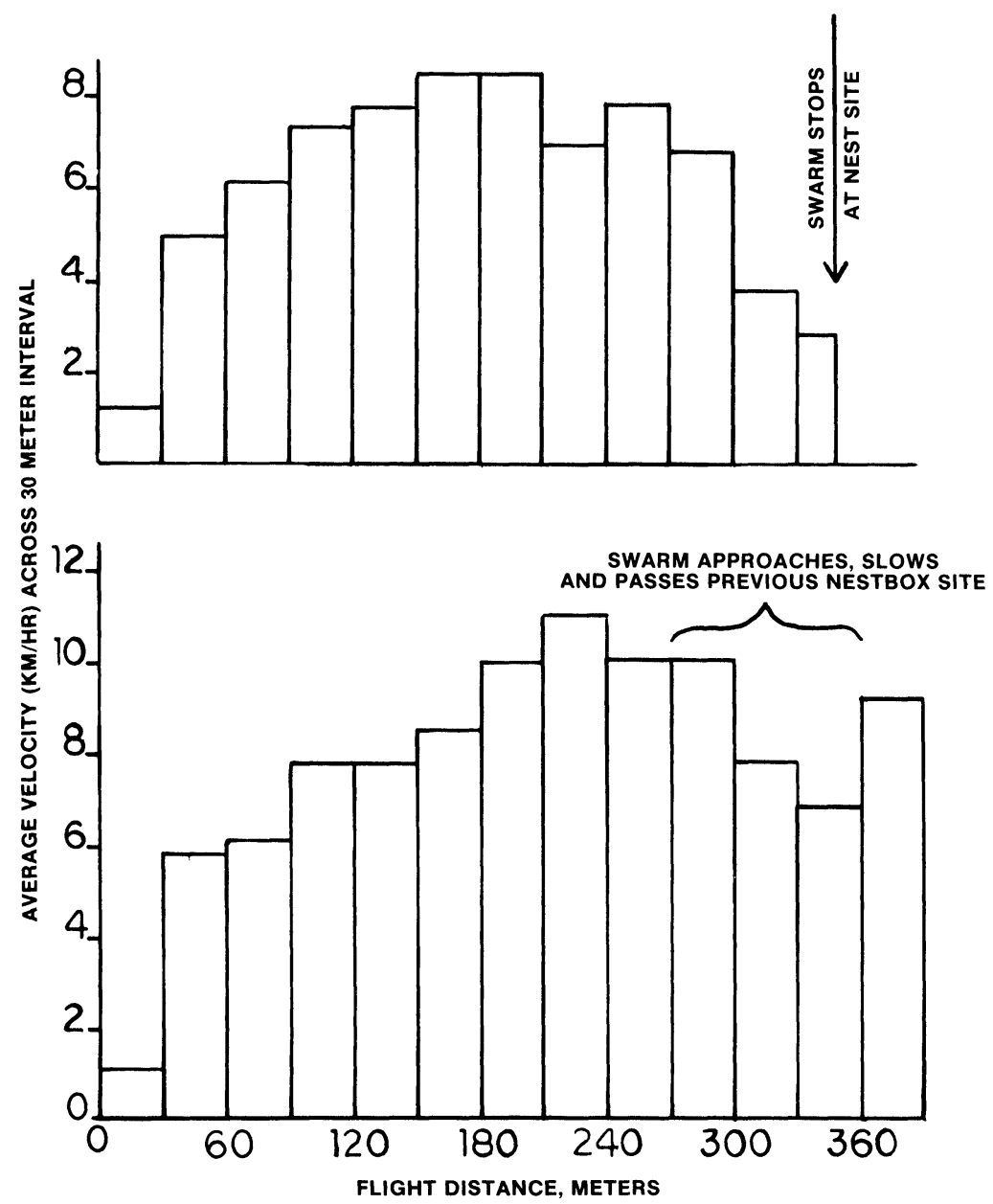

Fig. 2. Swarm flight velocities at various distances along the flight path. First flight (top plot) went $350 \mathrm{~m}$ and its velocities were measured throughout its flight. Second flight (bottom plot) went $580 \mathrm{~m}$ which was beyond the range of velocityrecording markers (see text for details). Note the slow start of both flights and the braking over the last $80 \mathrm{~m}$ in the first flight. The swarm also slowed upon approaching the first nest site on its second flight, but then again accelerated once past the first nest site. 
thus about $3 \mathrm{~m}$ above the earth's surface. The bees were dispersed throughout the swarm cloud; although density increased toward the center, there was no tight central cluster.

Even though the two swarm flights observed on Appledore Island involved relatively short distances $(350 \mathrm{~m}$ and $580 \mathrm{~m}$ ) the maximum flight speeds stated above may be representative for swarms making much longer flights. The Dyce Lab swarm, which flew more than $2000 \mathrm{~m}$ to its nest site, flew between stakes 435 and $605 \mathrm{~m}$ from its cluster site with an average velocity of $11.1 \mathrm{~km} / \mathrm{h}$. Beyond the $605 \mathrm{~m}$ point a fence and a field of brush prevented us from keeping even with the swarm, and so further velocity measurements could not be made. However, we feel that beyond the $605 \mathrm{~m}$ point the swarm increased its velocity little, if at all.

One riddle about swarm flight is the mechanism whereby scouts direct the other swarm bees toward the nest site. Lindauer (1955) observed bees streaking through a swarm in the direction of the nest site, and has suggested that these streaker bees are the swarm's scouts pointing the way. We have repeated Lindauer's observation of streakers; a small proportion of the bees in the swarm were moving rapidly in a direction generally oriented toward the nest site, amidst the slower, more wavering flight of their sisters. Avitabile and his coworkers (1975) suggested another mechanism of swarm guidance: scouts somehow lead swarms by releasing Nasanov pheromone. They report leading airborne swarms along zig-zag pathways, though in the general direction they would fly anyway, using an artificial mixture of the Nasanov secretion. One problem with their experiment is that they may have been providing the orientation signal used by swarms at the very end of their flights (see below), and so have influenced the swarms' flight patterns, but without duplicating the principal guidance system of swarms. This could be checked for by testing the orientation ability of a swarm whose members have had their Nasanov glands sealed shut with shellac.

The island swarm ended its two flights with quite elegant braking so that in both cases the swarm's center stopped within $10 \mathrm{~m}$ of the nest sites. The velocity plot in Fig. 2 (upper plot) indicates that the braking began at least $80 \mathrm{~m}$ before reaching the nest site. However, the mechanism of this braking, like that of the directional guidance, remains a mystery.

\section{Entry in the Nest Cavity}

Within seconds of the swarm cloud's stopping near the nest site, 
the number of bees releasing Nasanov pheromone at the nest entrance increased dramatically. Fig. 3 shows that $22 \mathrm{sec}$ after the swarm arrived 5 scenters had appeared at the entrance opening. Within another $35 \mathrm{sec}$ their number had leaped to 35-40. These initial scenters were primarily the swarm's scouts. Of the first 9 bees scenting at the nest entrance, $5(56 \%)$ carried blue marks. Even after over 100 bees, about half of them scenting, were visible at the nest entrance, $25 \%$ of the total was composed of marked bees. Because the blue-marked scouts were only $1.3 \%$ of the swarm population, it is clear that these scouts were contributing disproportionately in the
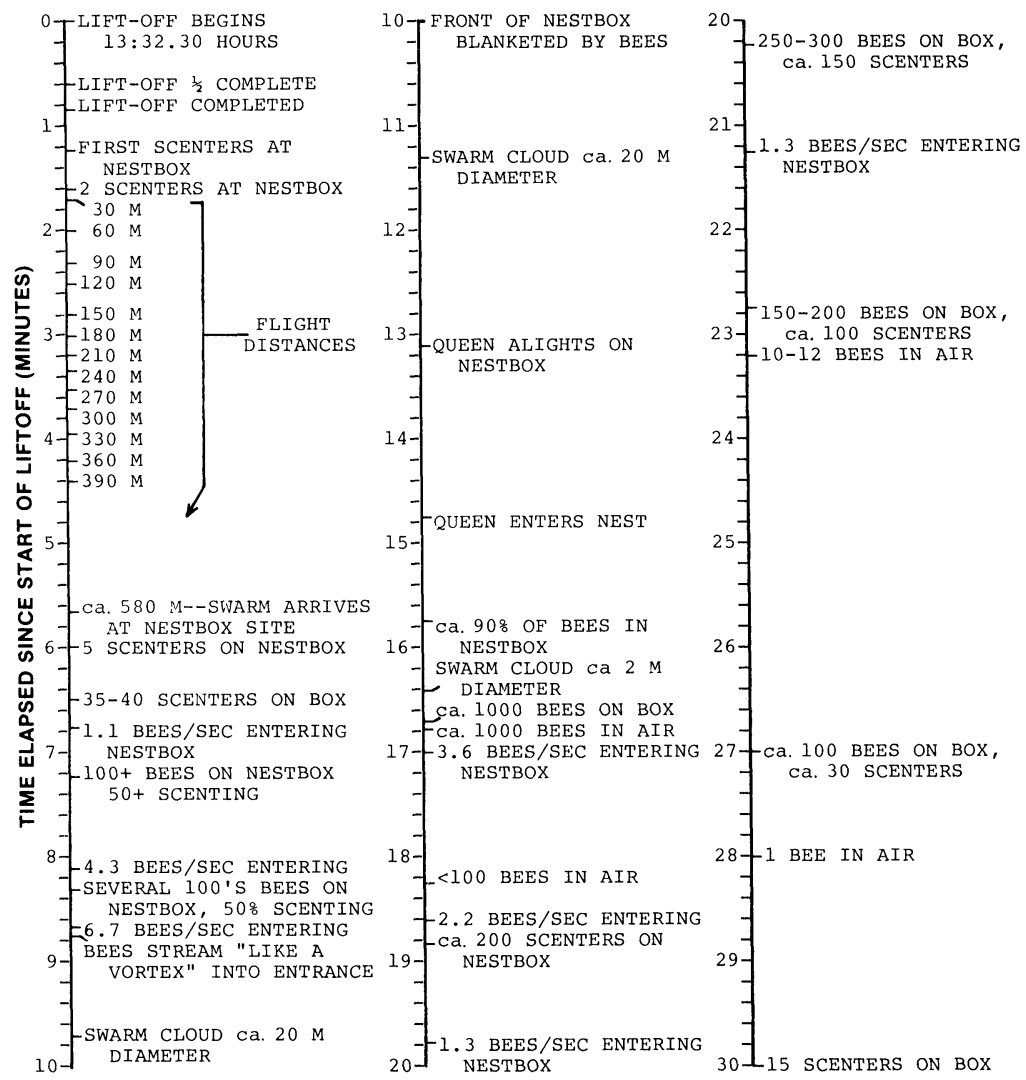

Fig. 3. Time line of events during the flight of a honey bee swarm and its subsequent entry into a new nest site. Note how within $30 \mathrm{~min}$ a swarm of about 11,000 bees broke cluster, flew $580 \mathrm{~m}$, and moved completely into a new nest cavity. 
earliest stages of signalling the location of the new nest entrance. This is logical, for at first only the scouts know the entrance location, and in nature the entrance opening - a small knothole, a little gap among the roots of a tree, or a narrow crack in a limb - can be quite inconspicuous. Thus, once the scouts had directed the swarm to the vicinity of the new nest site, they dropped out of the swarm cloud to pinpoint the nest's entrance chemically. The early unmarked scenters had probably scouted the nest site, but had not danced at the swarm cluster.

The remaining details of the swarm's entry into the nest cavity are presented in Fig. 3. In general summary, within 3 min of the swarm's arrival, bees had blanketed the nestbox's outer surface and were streaming into the nest cavity at nearly $7 \mathrm{bees} / \mathrm{sec}$, forming a twisting, whirlpool-like swirl of bees flowing into the entrance. In $9 \mathrm{~min}$ the queen entered. The bees did not require her presence in the nest to move inside, as they had to fly there. Within $10 \mathrm{~min}$ about $90 \%$ of the bees had entered, and finally, within 30 min of lift-off, nearly all 11,000 bees were safely inside their new home.

\section{ACKNOWLEDGMENTS}

We thank Dave De Jong, Robin Hadlock, Chris Kelley, Richard Nowogrodzki, Ken Ross, Jim Soha, and Lucia Turillo for help in chasing flying swarms. The Shoals Marine Laboratory community kindly tolerated hordes of honey bees zooming across their island. Supported by the American Philosophical Society.

\section{SUMMARY}

The social organization of honey bee swarm flight was studied throughout the period extending from completion of nest site selection, through cross-country flight, to entry into the nest cavity. First the scouts, numbering about $5 \%$ of the swarm, return from the nest site to the swarm cluster. Thus they are present at lift-off to guide the swarm's flight. Buzzing runs at the nest site trigger their return. Lift-off takes less than $60 \mathrm{sec}$ and is also stimulated by buzzing runs. The airborne swarm forms a circular cloud about $10 \mathrm{~m}$ in diameter and $3 \mathrm{~m}$ high. The flight starts very slowly, but accelerates to a velocity of 11 or more $\mathrm{km} / \mathrm{h}$. Some scouts pilot the swarm, apparently by performing streak flights through the swarm cloud, while others fly ahead to the new nest's entrance and release assembly 
pheromones. The swarm halts upon reaching the nest site, whereupon more scouts drop out of the swarm cloud and begin releasing assembly pheromones at the nest entrance to help pinpoint its location. During the next $20 \mathrm{~min}$ the bees flood into the nest cavity and so complete the swift, clean process of warm movement.

\section{REFERENCES}

Ambrose, J. T.

1976. Swarms in transit. Bee World 57, 101-109.

Avitabile, A., R. A. Morse And R. Boch

1975. Swarming honey bees guided by pheromones. Ann. Entomol. Soc. Amer. 68, 1079-1082.

$\mathrm{EsCH}, \mathrm{H}$.

1967. The sounds produced by swarming honey bees. Z. vergl. Physiol. 56, 408-411.

Fell, R. D., J. T. Ambrose, D. M. Burgett, D. De Jong, R. A. Morse and

T. D. SEeley

1977. The seasonal cycle of swarming in honey bees. J. apic. Res. 16, 170-173.

FRISCH, K. VON

1967. The dance language and orientation of bees. Belknap Press of Harvard University Press, Cambridge, Mass., 566 pp.

Lindauer, M.

1955. Schwarmbienen auf Wohnungssuche. Z. vergl. Physiol. 37, 263-324. MarTin, P.

1963. Die Steuerung der Volksteilung beim Schwärmen der Bienen. Zugleich ein Beitrag zum Problem der Wanderschwärme. Insectes Sociaux 10, $13-42$.

Michener, C. D.

1976. The social behavior of the bees. A comparative study. Belknap Press of Harvard University Press, Cambridge, Mass., 404 pp.

Morse, R. A. ANd T. D. Seeley

1978. Bait hives. Glean. Bee Cult. 106, 218-220, 242.

Seeley, T. D.

1977. Measurement of nest cavity volume by the honey bee (Apis mellifera). Behav. Ecol. Sociobiol. 2, 201-227.

Seeley, T. D. ANd R. A. Morse

1978. Nest site selection by the honey bee, Apis mellifera. Insectes sociaux 25, 323-337.

WILSON, E. O.

1971. The insect societies. Belknap Press of Harvard University Press, Cambridge, Mass. 548 pp. 

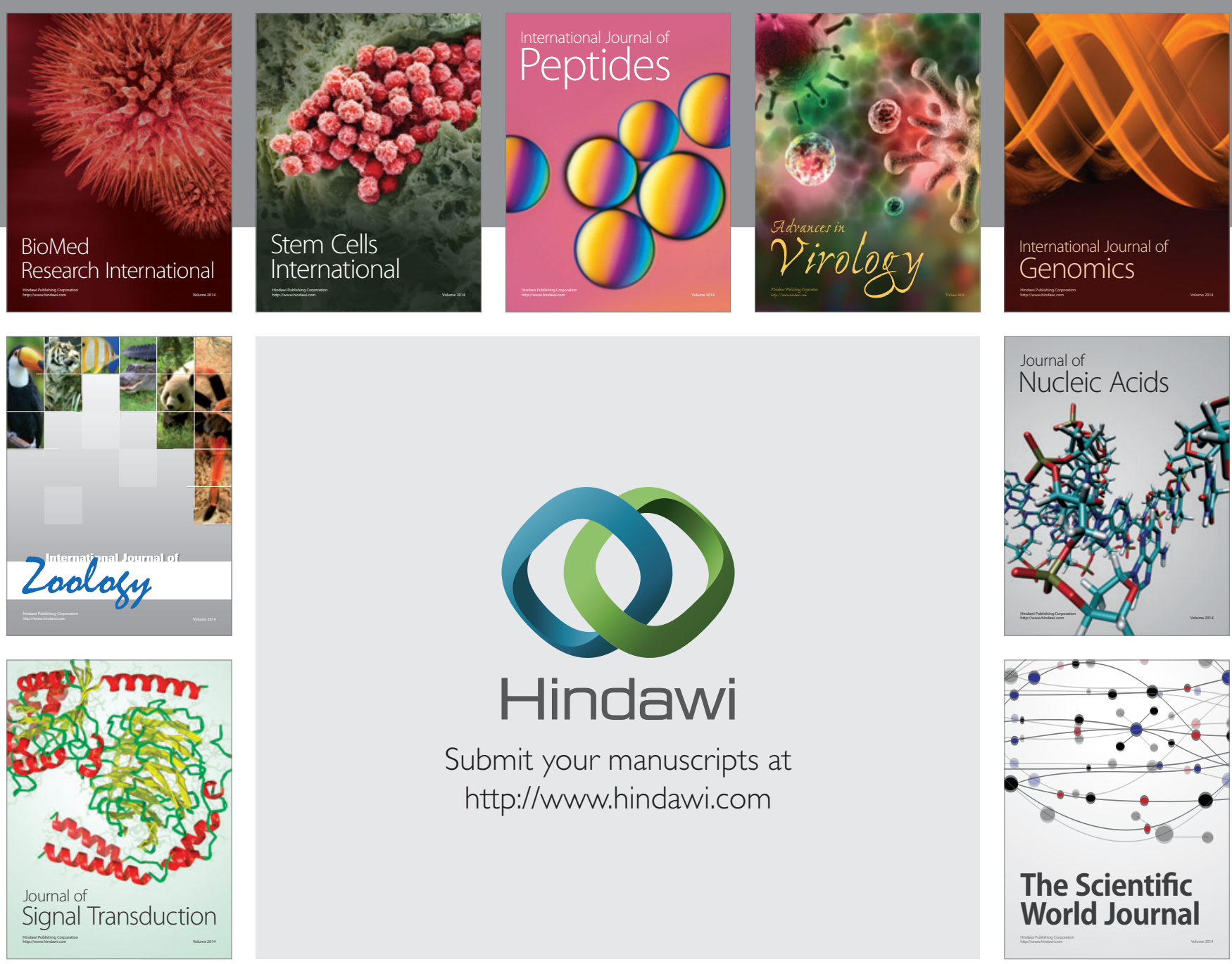

Submit your manuscripts at

http://www.hindawi.com
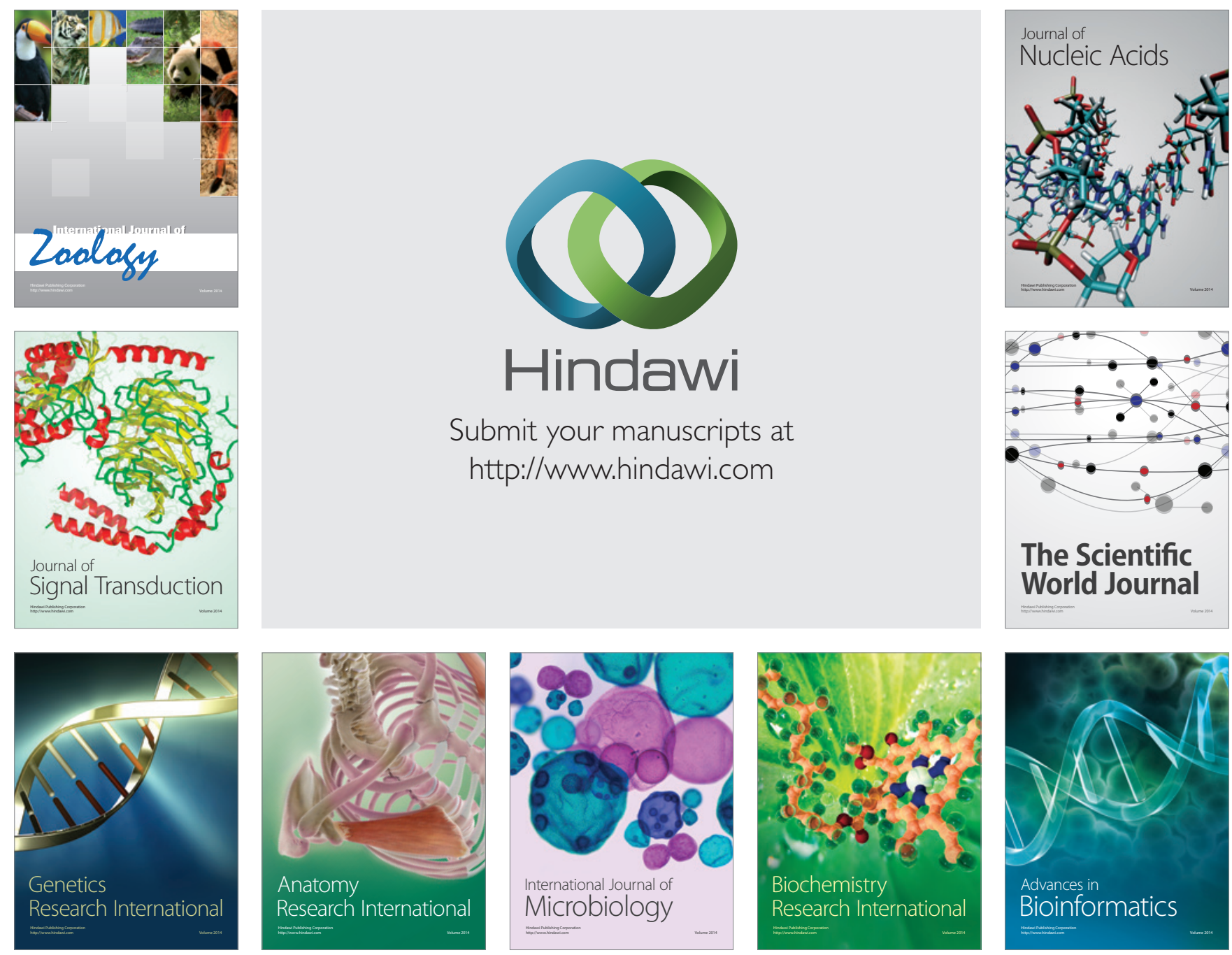

The Scientific World Journal
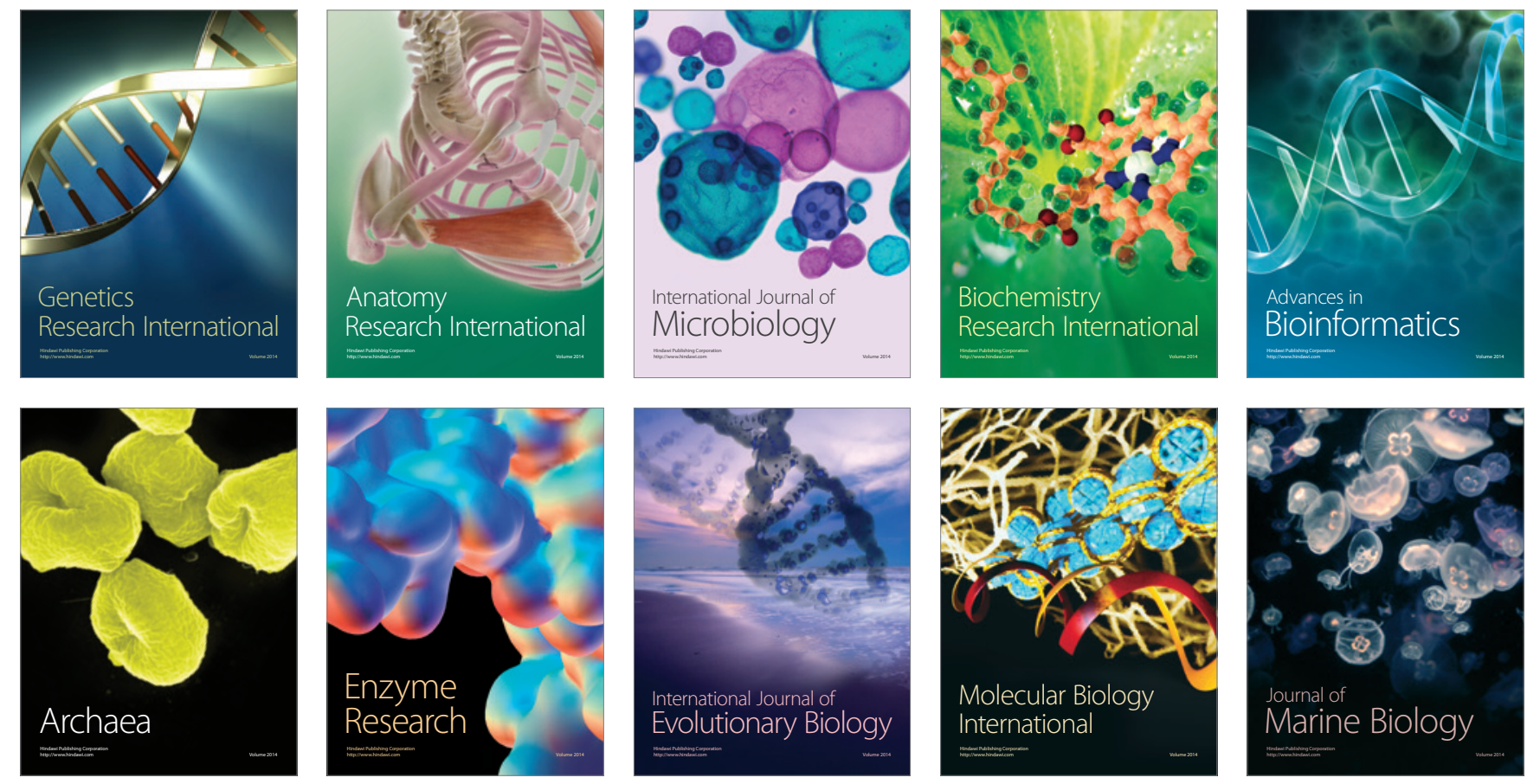